\title{
Summary of the Indonesian Guidelines for Diagnosis and Management of Osteoporosis
}

\begin{abstract}
Bambang Setyohadi, ${ }^{1}$ Errol Untung Hutagalung, ${ }^{2}$ John Marthin Frederik Adam, ${ }^{3}$ Marzuki Suryaatmadja, ${ }^{4}$
Nicolaas Cyrillus Budiparama, ${ }^{5}$ Siti Annisa Nuhonni Mustofa Jatim, ${ }^{6}$ Suharti Kartanegara Suherman, ${ }^{7}$ Kahar Kusumawijaya, ${ }^{8}$ Gunawan Tirtarahardja, ${ }^{9}$ Tanya Tatiana Marijam Rotikan, ${ }^{10}$ Achmad Rudijanto, ${ }^{11}$ Bagus Putu Putra Suryana ${ }^{12}$
\end{abstract}

\author{
${ }^{1}$ Division of Rheumatology, Department of Internal Medicine, Faculty of Medicine, University of Indonesia \\ 2 Division of Orthopaedics and Traumatology, Department of Surgery, Faculty of Medicine, University of Indonesia \\ ${ }^{3}$ Division of Endocrinology and Metabolism, Department of Internal Medicine, Faculty of Medicine, University of Hasanuddin \\ ${ }^{4}$ Department of Clinical Pathology, Faculty of Medicine, University of Indonesia \\ ${ }^{5}$ Department of Orthopaedic Surgery, Medistra Hospital, Jakarta \\ ${ }^{6}$ Department of Medical Physical Rehabilitation, Faculty of Medicine, University of Indonesia \\ ${ }^{7}$ Department of Clinical Pharmacology, Faculty of Medicine, University of Indonesia \\ ${ }^{8}$ Department of Radiology, Faculty of Medicine, University of Indonesia \\ ${ }^{9}$ Jakarta Osteoporosis Centre \\ ${ }^{10}$ Department of Sports Medicine, Faculty of Medicine, University of Indonesia \\ ${ }^{11}$ Division of Endocrinology and Metabolism, Department of Internal Medicine, Faculty of Medicine, University of Brawijaya \\ 12 Division of Rheumatology, Department of Internal Medicine, Faculty of Medicine, University of Brawijaya
}

\begin{abstract}
INTRODUCTION

Osteoporosis is a systemic skeletal disease characterized by low bone mass and microarchitectural deterioration of bone tissue, with a consequent increase in bone fragility and susceptibility to fracture. In 2001, the National Institute of Health (NIH) proposed a new definition for osteoporosis as a systemic skeletal disease characterized by compromised bone strength result in increase susceptibility to fracture. ${ }^{1}$
\end{abstract}

Osteoporosis is characterized by compromised bone strength and increase susceptibility to fracture. The problem of osteoporosis is increasing in Indonesia. The Indonesian Osteoporosis Guideline was developed to increase the awareness of medical practitioners in the detection and management of osteoporosis. Early detection and prevention is of paramount importance. Assessment of risk factors is an integral part of the management of osteoporosis.

Keywords : Indonesia, osteoporosis, guidelines, risk factors, diagnosis, management

The problem of osteoporosis will increase in developing countries, including Indonesia, with increased life expectancies and increased proportion of aged population. Data from a survey in 1990 showed that proportion of population with age of 55 or more was $9.2 \%$, which is increased $50 \%$ compared to data from the survey of $1971 .^{2}$ The Indonesian Guideline of Osteoporosis was developed to increase awareness of specialists, general practitioners and patients, about the detection and management of osteoporosis in Indonesia. Both the healthcare professionals and the patients can choose the optimal investigation and treatment options for the disease.

ISSN 0857-1074

Printed in the Philippines

Copyright $@ 2012$ by the JAFES

Received August 28, 2012. Accepted October 29, 2012.

\section{SUMMARY OF METHODOLOGY OF GUIDELINES DEVELOPMENT}

The Guidelines was developed by Indonesian Osteoporosis Association (Perhimpunan Osteoporosis Indonesia, PEROSI) and was officially launched during The $6^{\text {th }}$ Annual National Scientific Meeting of PEROSI in Malang, Indonesia on October 15, 2010.

\section{SUMMARY OF RECOMMENDATIONS}

\section{Risk factors}

Several conditions will increase the risk for osteoporosis. Risk factor evaluation is an important step in identifying patients with osteoporosis. (Table 1)

Risks for osteoporotic fracture are mainly determined by age and bone density. Other risk factors for osteoporotic fractures vary in different ages including risk of fall, vision problems, immobilization, sedative drugs and calcium intake. ${ }^{3,4}$

\footnotetext{
Corresponding author: Bambang Setyohadi, MD

Division of Rheumatology, Department of Internal Medicine,

Faculty of Medicine, University of Indonesia

Salemba 4, Central Jakarta, Indonesia

Tel. No.: (62-21) 31909152(office) / (62-61) 31930166 (office)

Fax No.: (62-21) 31936736

E-mail:b_setyohadi@yahoo.com; reumatik@indosat.net.id
} 


\section{Table 1. Risk factors for osteoporosis ${ }^{3}$}

\begin{tabular}{|c|c|}
\hline Age & $\begin{array}{l}\text { One decade increased of age is associated with } \\
1.4-1.8 \text { increased of osteoporosis risk }\end{array}$ \\
\hline \multirow[t]{3}{*}{ Genetic factor } & $\begin{array}{l}\text { Ethnicity (Caucasian and Oriental have greater } \\
\text { risk than black or Polynesian) }\end{array}$ \\
\hline & Sex \\
\hline & Family history \\
\hline \multirow[t]{5}{*}{ Environment } & Food, calcium deficiency \\
\hline & Physical activity and mechanical load \\
\hline & Drugs (corticosteroid, anticonvulsant, heparin) \\
\hline & Smoking \\
\hline & Alcohol \\
\hline \multirow{3}{*}{$\begin{array}{l}\text { Hormone and } \\
\text { chronic diseases }\end{array}$} & Estrogen deficiency \\
\hline & Androgen deficiency \\
\hline & $\begin{array}{l}\text { Gastrectomy, cirrhosis, thyrotoxicosis, } \\
\text { hypercortisolism }\end{array}$ \\
\hline \multirow[t]{4}{*}{ Physical of bone } & Bone density \\
\hline & Size and geometry of bone \\
\hline & Bone microarchitecture \\
\hline & Bone composition \\
\hline \multicolumn{2}{|c|}{$\begin{array}{l}\text { Adapted from Kanis JA. Assessment of fracture risk. Who should be } \\
\text { screened?. In: Favus MJ et al (Eds). Primer on the metabolic bone } \\
\text { disease and disorders of mineral metabolism. 5th ed. American Society } \\
\text { for Bone and Mineral Research. Washington DC. 2003: } 316-23\end{array}$} \\
\hline
\end{tabular}

\section{Diagnosis and clinical evaluation}

Clinical evaluation of patients with osteoporosis is aimed to identify risk factors, including life styles. History taking should include these points:

1. History of minimally traumatic fracture, decreased body height, increased kyphosis of the spine.

2. Chronic diseases that may increase risk for osteoporosis including endocrine disorders, renal diseases, liver diseases, vitamin D deficiency, hematologic diseases, gastrointestinal disease, neurologic diseases and rheumatic diseases.

3. History of drug consumption (corticosteroid, antiepileptic drug, cyclosporine, lithium, etc.).

4. Menstrual period (menarche, menopause, pregnancy).

5. Nutrition, including calcium intake.

6. Lifestyles (smoking, alcoholism, physical exercise).

7. Risk of fall.

8. History of breast tumor, malignancy, and vascular diseases that may be important in considering treatment options.

Physical examinations for patients with osteoporosis include height and weight. Other examinations include gait, bone deformities, leg-length inequality, spinal tenderness, and thyroid glands. Blue sclera are found in patients with osteogenesis imperfecta, associated with deafness, ligament hyperlaxity, joint hypermobility, and teeth abnormalities. In rickets, physical examination shows short stature, bone pain, craniotabes, costochondral joint prominence, and bowing deformity of longbone. Patients with hypocalcemia may present with tetany. Band keratopathy, which results from calcium phosphate deposition in the cornea, may be found in patients with primary hyperparathyroidism. ${ }^{5}$

\section{Bone biochemical markers}

Indication for bone biochemical marker measurement is to identify patients with osteoporosis risk, rapid bone loss, predict femoral fracture risk, to monitor patient with longterm steroid treatment, to evaluate treatment responses and study the pathogenesis of osteoporosis. Treatment with anti-resorptive agents will rapidly decrease bone remodeling, thus it can be detected using bone marker tests.

Bone formation markers include serum alkaline phosphatase, osteocalcin, procollagen-1-peptides, p1carboxyterminal propeptide, and p1-N-terminal propeptide. Bone resorption markers include urinary hydroxyproline, pyridinoline, deoxypyridinoline, and collagen-1-N-terminal telopeptide. Several conditions should be considered in interpreting results of bone markers, such as renal function, circadian rhythm, age and other diseases. ${ }^{6,7}$

\section{Radiographic examination}

Patients with osteoporosis should have a radiographic examination of the thoraco-lumbar spine to identify the presence of spinal fracture. However, plain radiographic examinations cannot detect early osteoporosis. Radiographic examinations have an important role in excluding other conditions such as bone metastasis, spondylitis, degenerative process, or primary malignancy on bone. ${ }^{2}$

\section{Bone densitometry}

Bone density test using dual energy $x$-ray absorptiometry (DXA) method is the standard test and widely used to measure the bone mineral density (BMD). This technique can be used to measure axial, peripheral and total body bone density. Indications for bone density test are to confirm diagnosis of osteoporosis, to calculate fracture risk and monitor treatment. ${ }^{8}$ (Table 2 )

\section{Table 2. Indication for Bone Mineral Density (BMD) test ${ }^{8}$ \\ 1 Women aged 65 or more \\ 2 Post-menopausal women aged less than 65 with risk factor \\ 3 Male aged 70 or more \\ 4 Adult with history of fragility fracture \\ 5 Adult with hip fracture risk \\ Adult with disease affecting bone metabolism \\ Adult consuming drugs affecting bone metabolism \\ Patient receiving pharmacologic treatment for osteoporosis \\ Treatment response monitoring \\ 10 Bone loss monitoring \\ Adapted from International Society for Clinical Densitometry. ISCD course syllabus: Use of bone densitometry for the diagnosis of} osteoporosis; 2009.

Results from BMD test using DXA technique are area bone density $\left(\mathrm{gram} / \mathrm{cm}^{2}\right)$, T-score, and Z-score. T-score is the number of standard deviations by which the patient's BMD differs from the mean peak BMD for young normal subjects of the same gender. Z-score is the number of standard deviations by which the patient's BMD differs from the mean BMD for subjects of the same age. The World Health Organization (WHO) classifies the BMD based on the T-scores. ${ }^{8}$ (Table 3) 
Table 3. BMD classifications

\begin{tabular}{cc} 
Classification & T-score \\
Normal & T-score $\geq-1$ \\
Osteopenia & T-score between -1 and -2.4 \\
Osteoporosis & T-score $\leq-2.5$ \\
Severe osteoporosis & T-score $\leq-2.5$ with fragility fracture \\
\hline Adapted from WHO Study Group. Assessment of fracture risk and its \\
application to screening for postmenopausal osteoporosis. World Health \\
Organ Tech Rep Ser 1994;843:1-129.
\end{tabular}

Fracture risk can be calculated using formula WHO FRAX Tool from the website www.shef.ac.uk/FRAX.

\section{Education and Prevention}

Regular physical exercise to maintain strength, flexibility and coordination of neuromuscular system may prevent falls. Adequate calcium and vitamin D intake, smoking and alcohol cessation should be advised for all patients with osteoporosis. The patient should also be informed regarding other diseases and drugs that may increase risk of osteoporosis. Patients who need long-term corticosteroid therapy should be treated with the lowest acceptable dose and should be discontinued as soon as possible. A patient with chronic inflammatory disease such as rheumatoid arthritis should be adequately treated to control the disease process. ${ }^{2}$

\section{Pharmacologic treatment}

1. Bisphosphonate antiresorptive agent

Bisphosphonates inhibit the action of osteoclasts. These drugs should be administered on an empty stomach, with 2 glasses of plain water, and patient should keep upright for at least 30 minutes to improve absorption and prevent reflux esophagitis. Bisphosphonate agents for osteoporosis treatment are risedronate (orally $5 \mathrm{mg} /$ day or $35 \mathrm{mg} /$ week or 150 $\mathrm{mg} / \mathrm{month}$ ), alendronate (orally $10 \mathrm{mg} /$ day or 70 $\mathrm{mg} /$ week), ibandronate (orally $2.5 \mathrm{mg} /$ day or 150 $\mathrm{mg} / \mathrm{month}$ or intravenously $3 \mathrm{mg} / 3$ months), and zoledronate (intravenously $5 \mathrm{mg} /$ year). ${ }^{2,10}$

\section{Raloxifene}

Raloxifene inhibits osteoclast differentiation through selective estrogen receptor modulator (SERM) action. It does not stimulate estrogen receptors in the endometrium and breast. The recommended dose for osteoporosis treatment is $60 \mathrm{mg} /$ day. $^{2}$

3. Hormonal replacement therapy

a. Post-menopausal women: conjugated estrogen $0.3125-1.25 \mathrm{mg} /$ day in combination with medroxyprogesterone acetate 2.5 - $10 \mathrm{mg} /$ day continuously. Mammography should be done beforethe treatment is started then re-ordered every year. Physicians should be aware of the findings of The Women's Health Initiative study of 2002, which reported potential side-effects of hormonal treatments.

b. Pre-menopausal women: conjugated estrogen is given on day 1 to 25 of the menstrual cycle, and medroxyprogesterone on day 15 to 25 , then both drugs stopped from day 26 to 28 .

c. Male: testosterone treatment is considered in male with testosterone deficiency.

4. Calcitonin

Calcitonin is indicated for conditions with increased bone resorption and hypercalcemia such as Paget's disease, osteoporosis and hypercalcemia of malignancy. Calcitonin decreases vertebral fracture risk, but not non-vertebral fracture. Subcutaneous calcitonin effectively decreases pain in spinal fracture. The recommended dose is $200 \mathrm{IU} /$ day intranasal.

5. Strontium ranelate

Strontium ranelate is an anti-osteporosis drug with dual effects by increasing osteoblast action and inhibiting osteoclast action. The recommended dose of strontium ranelate is 2 gram/day dissolved in water and taken at night 2 hours before or after meal.

6. Vitamin D

Vitamin D plays an important role in calcium absorption in the gastrointestinal tract. More than $90 \%$ of vitamin $\mathrm{D}$ is synthesized within the body from its precursor in the skin by ultraviolet light. In the elderly, activation of vitamin D in the skin is decreased, and results in increased frequency of vitamin D deficiency in elderly.

\section{Calcium}

Recommended daily calcium intake is $1200 \mathrm{mg}$. Calcium carbonate containing elemental calcium 400 $\mathrm{mg} / \mathrm{gram}$ is preferred. Other calcium preparations such as calcium phosphate, calcium citrate, calcium lactate and calcium gluconate contain lower elemental calcium i.e., $230 \mathrm{mg} / \mathrm{gram}, 211 \mathrm{mg} / \mathrm{gram}, 130 \mathrm{mg} / \mathrm{gram}$ and $90 \mathrm{mg} / \mathrm{gram}$, respectively.

8. Phytoestrogens

Phytoestreogens are derived from plants with similar chemical structure to $17 \beta$-estradiol and showing estrogenic effect. There are four groups of phytoestrogens including flavonoids, lignans, coumestans and stilben. Isoflavon (mainly genistein and daidzein) is a subgroup of flavonoids, already investigated for treatment of osteoporosis. Effective dose of isoflavon is $20-80 \mathrm{mg} /$ day. ${ }^{12}$ 


\begin{tabular}{|c|c|c|}
\hline $\begin{array}{c}\text { Food } \\
\text { category }\end{array}$ & Food ingredients & $\begin{array}{c}\text { Calcium }(\mathrm{mg}) / \\
100 \text { grams }\end{array}$ \\
\hline Dairy & Cow's milk & 116 \\
\hline \multirow[t]{4}{*}{ products } & Lamb's milk & 129 \\
\hline & Human breast milk & 33 \\
\hline & Cheese & $90-1180$ \\
\hline & Yoghurt & 150 \\
\hline \multirow[t]{4}{*}{ Fish } & Rebon & 769 \\
\hline & Fresh teri & 500 \\
\hline & Sardines (canned with bones) & 354 \\
\hline & Papaya leaves & 353 \\
\hline \multirow[t]{3}{*}{ Vegetables } & Spinach & 267 \\
\hline & Chinese cabbage (Sawi) & 220 \\
\hline & Broccoli & 110 \\
\hline \multirow[t]{4}{*}{ Legumes } & Yardlong beans & 347 \\
\hline & Soybean milk (250 mL) & 250 \\
\hline & Tempe & 129 \\
\hline & Tofu & 124 \\
\hline \multirow[t]{2}{*}{ Cereals } & Jali (Coix lacryma-jobi) & 213 \\
\hline & Oatmeals & 53 \\
\hline
\end{tabular}

\section{Surgical treatment}

Surgical treatment is indicated in a patient with fracture, mainly hip fracture. In elderly with hip fracture, surgical treatment should be planned immediately in order to prevent long-term immobilization and further complications. The patient should also be treated with calcium and anti-osteoporosis agent after the operation. ${ }^{2}$

\section{Treatment evaluation}

BMD re-examination at 1 to 2 year intervals can be done to evaluate treatment responses in patients with osteoporosis. If the BMD can be maintained or remains stable in one yea, the treatment is successful and the bone resorption activity is suppressed. Bone metabolism markers can also be used to evaluate treatment responses, and can detect the changes earlier, within 3-4 months. ${ }^{2}$

\section{CONCLUSION}

Osteoporosis can be prevented with careful assessment of the risk factors. Since the management of osteoporosis requires high cost and long-term monitoring, it is recommended that early detection and prevention especially among high risk population.

\section{References}

1. NIH consensus development panel on osteoporosis prevention and therapy. Osteoporosis prevention, diagnosis and therapy. JAMA 2001;285:785-95.

2. Setyohadi Bea. Panduan Diagnosis dan Penatalaksanaan Osteoporosis. 2010:1.

3. Kanis J. Assessment of fracture risk. Who should be screened? In: al $\mathrm{FMe}$, ed. Primer on the metabolic bone disease and disorders of mineral metabolism. 5th ed. Washington DC: American Society for Bone and Mineral Research; 2003:316-23.

4. Kanis J, Borgstrom F, De Laet C et al. Assessment of fracture risk. Osteoporosis Int 2005;16:581-9.

5. Siklarin P, Shoback DM, Langman CB. History and physical examination of osteoporosis. In: al FMe, ed. Primer on the metabolic bone disease and disorders of mineral metabolism. 5th ed. Washington DC: American Society for Bone and Mineral Research; 2003:143-4.

6. Looker A, Bauer DC, Chesnut CH III, et al. Clinical use of biochemical markers of bone remodelling: Current status and future direction. Osteoporosis Int 2000;11:467-80.

7. Delmas Pea. Expert committee of the committee of scientific advisors of the International Osteoporosis Foundation for the use of bone markers in postmenopausal osteoporosis. Osteoporosis Int 2000;Suppl 6:S2-17.

8. International Society for Clinical Densitometry. ISCD course syllabus: Use of bone densitometry for the diagnosis of osteoporosis; 2009.

9. WHO Study Group. Assessment of fracture risk and its application to screening for postmenopausal osteoporosis. World Health Organ Tech Rep Ser 1994;843:1-129.

10. Black D, Rosen, CJ. Biphosphonates for the Prevention and Treatment of Osteoporosis. In: MJ F, ed. Primer on the Metabolic Bone Diseases and Disorders of Mineral Metabolism Washington D.C.: American Society for the Bone and Mineral Research; 200.

11. Direktorat Gizi Departemen Kesehatan RI. Daftar Komposisi Bahan Makanan: Bhratara; 1996.

12. Meunier P. Osteoporosis: Diagnosis and management. 1st ed. London: Mosby; 1998.

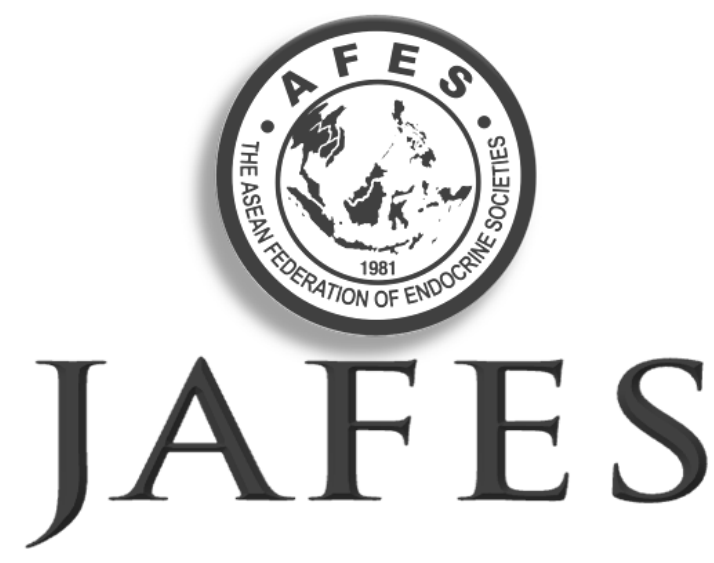

\section{Clinical controversies and disease updates are also welcome. Instructions to Authors available at www.ASEAN-endocrinejournal.org.}

